\title{
Identification of prognostic markers of lung cancer through bioinformatics analysis and in vitro experiments
}

\author{
BO LING ${ }^{1}$, XIANJIU LIAO ${ }^{1}$, YUANHE HUANG ${ }^{2}$, LINGLING LIANG ${ }^{1}$, \\ YAN JIANG ${ }^{3}$, YAQIN PANG ${ }^{4}$ and GUANGZI QI ${ }^{4}$ \\ Colleges of ${ }^{1}$ Pharmacy and ${ }^{2}$ Basic Medical Sciences, Youjiang Medical University for Nationalities, Baise, \\ Guangxi 533000; ${ }^{3}$ Medical College, Guangxi University, Nanning, Guangxi 530004; ${ }^{4}$ College of Public Health \\ and Management, Youjiang Medical University for Nationalities, Baise, Guangxi 533000, P.R. China
}

Received May 13, 2019; Accepted October 15, 2019

DOI: 10.3892/ijo.2019.4926

\begin{abstract}
Lung cancer is one of the most common types of cancer worldwide. Understanding the molecular mechanisms underlying the development and progression of lung cancer may improve early diagnosis, treatment and prognosis. The aim of the present study was to examine the pathogenesis of lung cancer and to identify potentially novel biomarkers. Gene expression datasets of patients with lung cancer were obtained from the Gene Expression Omnibus. Genes which were most closely associated with lung cancer (core genes) were screened by weighted gene co-expression network analysis. In vitro cell based experiments were further utilized to verify the effects of the core genes on the proliferation of lung cancer cells, adhesion between cells and the matrix, and the associated metabolic pathways. Based on WGCNA screening, two gene modules and five core genes closely associated with lung cancer, including immunoglobulin superfamily member 10 (IGSF10) from the turquoise module, and ribonucleotide reductase regulatory subunit M2, protein regulator of cytokinesis 1, kinesin family member (KIF)14 and KIF2C from the brown module were identified as relevant. Survival analysis and differential gene expression analysis showed that there were significant differences in IGSF10 expression levels between the healthy controls and patients with lung cancer. In patients with lung cancer, IGSF10 expression was decreased, and the overall survival time of patients with lung cancer was significantly shortened. An MTT and colony formation assay showed that IGSF10-knockout significantly increased proliferation of lung
\end{abstract}

Correspondence to: Professor Yaqin Pang or Professor Guangzi Qi, College of Public Health and Management, Youjiang Medical University for Nationalities, 98 Urban and Rural Road, Baise, Guangxi 533000, P.R. China

E-mail: pangyaqin@126.com

E-mail: qiguangzi2004@163.com

Key words: lung cancer, Gene Expression Omnibus, weighted gene co-expression network analysis, immunoglobulin superfamily member 10 , proliferation, prognostic marker cancer cells, and Transwell assays and adhesion experiments further suggested that the adhesion between cells and the matrix was significantly increased in IGSF10-knockout cells. Gene Set Enrichment Analysis showed that the expression level of IGSF10 was significantly associated with the activation of the integrin- $\beta 1 /$ focal adhesion kinase (FAK) pathway. Western blotting revealed that knockout of IGSF10 resulted in the activation of the integrin- $\beta 1 / F A K$ pathway, as the protein expression levels of integrin- $\beta 1$, phosphorylated (p)-FAK and $\mathrm{p}$-AKT were significantly upregulated. Activation of the integrin- $\beta 1 / F A K$ pathway, following knockout of IGSF10, affected the proliferation and adhesion of lung cancer cells. Therefore, IGSF10 my serve as a potential prognostic marker of lung cancer.

\section{Introduction}

Lung cancer is a common malignant tumour of the respiratory system and the morbidity and mortality rates rank among the highest worldwide. Lung cancer is a disease with multiple complex molecular networks underlying its development and progression (1). In recent years, there have been notable advancements in the understanding of the molecular mechanisms involved in lung adenocarcinoma, which has resulted in the identification of numerous targeted drug therapies, which exhibit notably improved survival and prognosis in patients with lung cancer (2-4). Gefitinib, erlotinib and bevacizumab are the most frequently used drugs for treatment of lung cancer (5-7). However, patients may exhibit adverse reactions, drug resistance and other complications when assigned regimens containing these drugs (8-10). Understanding the molecular mechanisms underlying the development and progression of lung cancer may assist in the development of treatment measures with enhanced efficacy and improved outcomes, and improve early detection in patients with lung cancer.

The various stages of lung cancer are associated with up- and downregulation of various genes. Wang et al (11) demonstrated that microRNA (miR)-513b regulates the effects of high mobility group box 3 on cell proliferation, apoptosis, invasion and migration by regulating the mTOR signalling pathway in non-small cell lung cancer (NSCLC). Qiu et al (12) 
demonstrated that circFGFR3 increases the expression of galetin-1, phosphorylated (p)-AKT and p-ERK1/2 through competitive binding with miR-22-3p, thus promoting the invasion and proliferation of NSCLC. Upregulated expression of circFGFR3 is associated with a poor prognosis in patients with lung cancer (13). However, studies based on individual gene expression are insufficient for the investigation of the mechanism of lung cancer. Interactions between genes influence gene expression and a comprehensive understanding of the direct and indirect interactions between genes will greatly assist in developing a comprehensive description of cell mechanisms and functions both in physiologically healthy cells and in cancerous cells.

Advances in genomics, transcriptomics and sequencing technology, and the used of gene co-expression networks has developed and been expanded in biological research (14-16). Gene co-expression networks are widely used in the analysis of high-throughput chip data, RNA sequencing, DNA methylation and other types of genome data analyses (17-19). The most representative gene co-expression network is the weighted gene co-expression network analysis (WGCNA) (20). WGCNA has provided meaningful advances in our understanding of multi-species gene analysis, such as in humans and mice, and has become a widely used network analysis tool (21). In addition, the core genes obtained by network screening can be supplemented and verified by biological experiments to further explore and verify the identified mechanisms. This strategy avoids a potentially blind approach in experimental research and confirms the validity or highlights potential flaws of network analyses. Sun et al (22) identified CD36 as a core gene based on WGCNA screening. Differential expression and increased methylation of CD36 in lung cancer were confirmed by reverse transcription-quantitative PCR and western blotting, confirming the inhibitory effect of CD36 in the development of lung cancer (22). An et al (23) used Gene Set Enrichment Analysis (GSEA) and WGCNA to identify potential metabolic pathways associated with the core gene KIBRA, which is involved in regulation of lung cancer. KIBRA reduced proliferation and invasion of lung cancer cells and induced apoptosis, and this was verified in in vitro experiments (23).

The aim of the present study was to identify core genes associated with lung cancer and construct a WGCNA network based on data obtained from Gene Expression Omnibus (GEO) and analyse the data in regards to the clinical information and survival information of the patients. Additionally, the effects of immunoglobulin superfamily member 10 (IGSF10) on proliferation of lung cancer cells, cell-cell and cell-extracellular matrix adhesions, and associated metabolic pathways were determined in vitro. The mechanisms of the identified core genes were further explored highlighting potential biomarkers for the diagnosis of patients with lung cancer.

\section{Materials and methods}

Selection criteria and acquisition of the data. The GSE19804 lung cancer dataset (24) was obtained from GEO (https://www.ncbi.nlm.nih.gov/geo/). The dataset contained information from non-smoking women with NSCLC. NSCLC accounts for $85 \%$ of all lung cancer cases (25), and the majority of cases of lung cancer in male patients are associated with smoking, whereas the majority of lung cancer cases in females are not associated with smoking $(26,27)$. In the present study, biomarkers associated NSCLC in non-smoking female patients were examined. A total of 120 samples were analysed, and the information did not include normal tissue from patients with pneumonia, but did contain information from the normal adjacent lung tissue samples (60 tumour tissues and 60 adjacent tissues). The Affymetrix Human Genome U133 Plus 2.0 Array (Affymetrix; Thermo Fisher Scientific, Inc.) annotation platform was utilized to match probes with gene names. Relevant clinical information was used for WGCNA.

Construction of a gene co-expression network. The gene co-expression network was constructed using the WGCNA package in $\mathrm{R}$ (https://horvath.genetics.ucla. edu/html/CoexpressionNetwork/Rpackages/WGCNA/). The top $25 \%$ of genes showing the highest levels of variance were screened for the construction of a weighted co-expression network. The power value was calculated through the pickSoftThreshold function of WGCNA package. The dynamic tree cutting algorithm of WGCNA package was used to segment the network module.

Identification of important clinical modules. The correlation between modules and clinical features was evaluated using Pearson's correlation coefficient analysis. Clinical information included age and stage. The correlation between the eigengenes of the module and the clinical features were assessed to identify key modules. Gene significance (GS) was defined as the linear relationship between gene expression and clinical information. Module significance was defined as the average GS, screening for all genes in each module to identify key modules.

Gene Ontology (GO) and Kyoto Encyclopaedia of Genes and Genomes (KEGG) enrichment analysis. GO enrichment analysis and KEGG enrichment analysis were performed on key modules using the $\mathrm{R}$ package clusterProfiler 3.14.0 (http://www.bioconductor. org/packages/release/bioc/html/clusterProfiler.html). $\mathrm{P}<0.05$ was defined as a meaningful enrichment analysis result.

Identification of hub genes. Genes exhibited high levels of connectivity to nodes in a module were considered to have important functions. A key module network diagram was created using Cytoscape 3.72 (https://cytoscape.org) to screen for the top 30 genes with the highest levels of connectivity in the module network.

Survival analysis. GEPIA (http://gepia.cancer-pku.cn/) is a website used to analyse RNA expression data of tumours and normal samples in The Cancer Genome Atlas (TCGA) database (https://portal.gdc.cancer.gov/). GEPIA was used to perform survival analysis of the previously identified hub genes. The gene expression was stratified into high and low expression according to the median values, and the significance of expression of these genes on survival was determined using a log-rank test. 
Dataset validation. GEPIA contains RNA sequencing expression data from 9,736 tumor samples and 8,587 normal samples from 33 malignant tumors of TCGA and GTEx (28). In the present study, lung adenocarcinoma and lung squamous cell carcinoma data from TCGA database were used to validate gene expression data for selected key genes, and the function of 'BoxPlots' was run to analyze whether the hub gene was differentially expressed between lung adenocarcinoma and lung squamous cell carcinoma and normal samples.

Oncomine analysis. Oncomine (https://www.oncomine.org/) is a database and integrated data mining platform based on gene chip, in which the data can be screened and mined according to determinable requirements. In the present study, the following conditions were set: i) Cancer Type, 'Lung Cancer'; ii) Gene, 'IGSF10'; iii) Analysis Type, 'Cancer vs. Normal Analysis'; iv) critical value setting conditions '( $\mathrm{P}$ value $<1 \mathrm{E}-4$, fold change $>2$, gene rank=top 10\%)'. Hou et al (29) and Okayama et al (30) lung datasets were determined to meet the selection criterion.

Reagents. RPMI-1640 medium was purchased from Gibco; Thermo Fisher Scientific, Inc. FBS was purchased from Biological Industries. Integrin- $\beta 1$ (catalog no. 9699S), p-FAK (catalog no. 8556S), FAK (catalog no. 71433S), p-AKT (catalog no. 4060S) and AKT (catalog no. 4691S) primary antibodies were purchased from Cell Signalling Technology, Inc. The IGSF10 antibody was purchased from Novus Biologicals, Ltd. (catalog no. H00285313-A01). The $\beta$-actin antibody (catalog no. sc-47778), secondary goat anti-rabbit antibody (horseradish peroxidase-conjugated; catalog no. sc-2004) and secondary goat anti-mouse antibody (horseradish peroxidase-conjugated; catalog no. sc-2005) were purchased from Santa Cruz Biotechnology, Inc.

Cell culture. Human lung adenocarcinoma cell lines H1299, HCC827, A549 and PC9 were cultured in RPMI-1640 medium supplemented with $10 \% \mathrm{FBS}$, and incubated at $37^{\circ} \mathrm{C}$ with $5 \% \mathrm{CO}_{2}$. Cells in the logarithmic growth phase were used for subsequent experiments.

Reverse transcription-quantitative $(R T-q) P C R$. Cell culture dishes were placed on ice, culture medium was removed and cells were washed three times with PBS. Total RNA was extracted using a Trizol ${ }^{\circledR}$ kit (Invitrogen; Thermo Fisher Scientific, Inc.). The extracted RNA was reverse transcribed into cDNA using a PrimeScript ${ }^{\circledR}$ RT Reagent kit with DNA Eraser (Takara Bio Inc.) according to the manufacturer's instructions. qPCR was performed using SYBR $^{\circledR}$ Premix EX TaqTM II (Tli RNaseH Plus, Takara Bio, Inc.) on an Applied Biosystems ${ }^{\circledR} 7500$ Real-Time PCR System (Thermo Fisher Scientific, USA), and 18s was used as the internal reference gene. The qPCR conditions were $10 \mathrm{~min}$ at $95^{\circ} \mathrm{C}$ followed by 45 cycles at $95^{\circ} \mathrm{C}$ for $15 \mathrm{sec}$ and $58^{\circ} \mathrm{C}$ for $34 \mathrm{sec}$. The sequences of the primers used were: IGSF10 forward, 5'-CTGGGGAGTCCAATTGCTGT-3' and reverse, 5'-GCTGCCTTTGCTGACATC-3'; and 18S forward, 5'-GGTGAAGGTCGGAGTCAACGG-3' and reverse, 5'-GAGGTCAATGAAGGGGTCATTG-3'.
Western blotting. Protein samples were lysed at $4^{\circ} \mathrm{C}$ using RIPA lysis buffer (1\% Triton X-100, $50 \mathrm{mM}$ Tris- $\mathrm{HCl}$ $\mathrm{pH}$ 7.4, $150 \mathrm{mM} \mathrm{NaCl}, 10 \mathrm{mM}$ EDTA, $100 \mathrm{mM} \mathrm{NaF}$, $1 \mathrm{mM} \mathrm{Na3VO} 4,1 \mathrm{mM}$ PMSF and $2 \mu \mathrm{g} / \mathrm{ml}$ aprotinin) for $40 \mathrm{~min}$. The samples were centrifuged at $18,620 \mathrm{x} \mathrm{g}$ for $25 \mathrm{~min}$ at $4^{\circ} \mathrm{C}$. The supernatants were obtained, and the protein concentration was quantified using the Coomassie Brilliant Blue method (31). Samples were mixed with $3 \mathrm{x}$ sample buffer solution and boiled for $5 \mathrm{~min}$. Protein samples were loaded on a 12\% SDS-gel (30-50 $\mu \mathrm{g} /$ lane) and resolved using SDS-PAGE for $3 \mathrm{~h}$. Resolved proteins were transferred to a nitrocellulose membrane (voltage, $2 \mathrm{mV} / \mathrm{cm}^{2}$ for $120 \mathrm{~min}$ ). Membranes were blocked with $5 \%$ skimmed milk for $1 \mathrm{~h}$ at room temperature, and the membrane was cut according to the molecular weight of the protein of interest based on a pre-stained protein ladder. Subsequently, the membranes were incubated with the primary antibody overnight at $4^{\circ} \mathrm{C}$. The primary antibody dilutions were prepared as follows: Integrin- $\beta 1,1: 1,000$; p-FAK, 1:500; FAK, 1:1,000; p-AKT, 1:1,000; AKT, 1,000; IGSF10, 1:1000; and $\beta$-actin, 1:500. The following day, the membranes were washed four times with TBST buffer $(10 \mathrm{mM}$ Tris- $\mathrm{Cl}$ $\mathrm{pH} 7.4,150 \mathrm{mM} \mathrm{NaCl}, 0.1 \%$ Tween-20) and incubated with the appropriate secondary antibody $(1: 2,000)$ for $30 \mathrm{~min}$ at room temperature. Membranes were washed again four times again with TBST and signals were visualized using enhanced chemiluminescence reagent (SuperSignal Western Pico Chemiluminescent Substrate; Pierce; Thermo Fisher Scientific, Inc.). Densitometry analysis was performed using ImageJ Pro Plus 6.0 (National Institutes of Health).

Liposome-mediated cell transfection. Healthy cells in the logarithmic growth phase were trypsinized to a single cell suspension, plated in a 6 -well plate at a density of $2 \times 10^{5} /$ well and incubated overnight. Once the cells had adhered, they were transfected with $5 \mu$ IGSF10-small interfering (si)RNA or negative control (NC)-siRNA from Santa Cruz Biotechnology, Inc. The sequences of the IGSF10-specific siRNA and NC-siRNA were 5'-AGGUGUUUCCCAGAUUACCdTdt-3' and 5'-UUCUCCGAACGUGUCACGUTT-3', respectively. Lipofectamine ${ }^{\circledR} 2000(5 \mu \mathrm{l})$ was mixed with RPMI-1640 medium and left to stand for $5 \mathrm{~min}$ at room temperature. Subsequently, $10 \mu \mathrm{l}$ siRNA was added to $240 \mu \mathrm{l}$ RPMI-1640 medium and mixed with the Lipofectamine ${ }^{\circledR} 2000$ and RPMI-1640 mixture prepared above. The 6-well plates containing the cells were incubated for $20 \mathrm{~min}$, after which the medium was removed and $1.5 \mathrm{ml}$ RPMI-1640 medium was added, and the transfection solution prepared above was added. Cells were incubated with the transfection mixture for 6-8 h, after which the medium was replaced with supplemented RPMI-1640 medium.

Cell viability. To determine cell viability, cells were prepared and transfected as described above. The absorbance values were measured after transfection to evaluate the effect of IGSF10-knockdown on cell viability. To measure viability, $20 \mu \mathrm{l}$ MTT solution $(5 \mathrm{mg} / \mathrm{ml})$ was added to each well and incubated for another $4 \mathrm{~h}$. Subsequently, the supernatant was removed, $200 \mu 1 \mathrm{DMSO}$ was added to each well the plate was gently agitated until the formazan crystals were completely 
dissolved. Absorbance was measured at $570 \mathrm{~nm}$ with a microplate reader at $0,24,48,72$ and $96 \mathrm{~h}$ after MTT was added.

Colony formation assay. A total of $48 \mathrm{~h}$ after transfection, 500 cells were plated in a 12 -well culture plate and incubated. The growth status of the cells was observed every 3 days. After 2 weeks, the colonies were fixed with formaldehyde for 10 min at room temperature and stained with $0.5 \%$ crystal violet solution for $40 \mathrm{~min}$ at room temperature. Three fields were randomly counted under a light microscope (magnification, $\mathrm{x} 40)$. The number of colonies was calculated.

Transwell migration and invasion assays. Cells were trypsinized, and the samples were centrifuged at $300 \mathrm{x}$ g for $5 \mathrm{~min}$ at room temperature. After discarding the supernatant, the samples were resuspended in RPMI-1640 medium, centrifuged at $300 \mathrm{x} \mathrm{g}$ for $5 \mathrm{~min}$ at room temperature to wash cells with PBS. Cells were resuspended in $200 \mu$ l RPMI-1640 medium and the density of cells was determined by hemocytometer. For the invasion assays, Transwell membranes were coated with Matrigel (BD Biosciences). A total of $1 \times 10^{4}$ cells were placed in the upper chamber of a microporous (8- $\mu \mathrm{m}$ pores) Transwell insert. In the lower chamber, $500 \mu$ l RPMI-1640 supplemented with 10\% FBS was added and the cells were incubated. Migration and invasion was determined by counting the number of cells that had successfully migrated through the membrane (migration) or invaded through the Matrigel matrix (invasion). After $24 \mathrm{~h}$, the chamber was removed, cells which had not migrated or invaded were removed using a cotton swab, and the insert was dried at room temperature. Cells were subsequently fixed with $4 \%$ paraformaldehyde for $10 \mathrm{~min}$ at room temperature and dyed for 1 min using the Wright Stain Method (32) at room temperature. Cells were incubated with diluted Giemsa and re-dyed for $40 \mathrm{~min}$ at room temperature. The filter membrane was dried with a cotton swab, and the sample was photographed.

Wound healing assay. The cells were selected, digested and counted, and then inoculated into 6-well culture plates and incubated overnight. The next day, IGSF10-siRNA and NC-siRNA were used for transfection. A total of $48 \mathrm{~h}$ after transfection, when the confluence was close to $100 \%$, a monolayer of the cells was scratched with a $200-\mu$ l pipette tip and photographed using an inverted microscope at $\times 200$. The 6-well culture plate was placed in the incubator and photographed again $24 \mathrm{~h}$ later. The areas of the scratches in the two photos were compared.

Adhesion experiment. Cells were plated in 96-well plates, which were precoated with $10 \mu \mathrm{g} / \mathrm{ml}$ Matrigel, overnight at $37^{\circ} \mathrm{C}$, at a density of $2 \times 10^{4}$ cells/well with serum-free RPMI-1640. Following incubation at $37^{\circ} \mathrm{C}$ for $30 \mathrm{~min}$, cells that did not adhere to the plates were washed off with PBS. Adherent cells were fixed in $4 \%$ paraformaldehyde for $10 \mathrm{~min}$ at room temperature, stained with Wright-Giemsa for $40 \mathrm{~min}$ at room temperature, counted in five random fields under a light microscope (magnification, x200) and analyzed statistically.

Flow cytometry. The effect of IGSF10-siRNA on apoptosis was detected. The cells to be treated were digested with
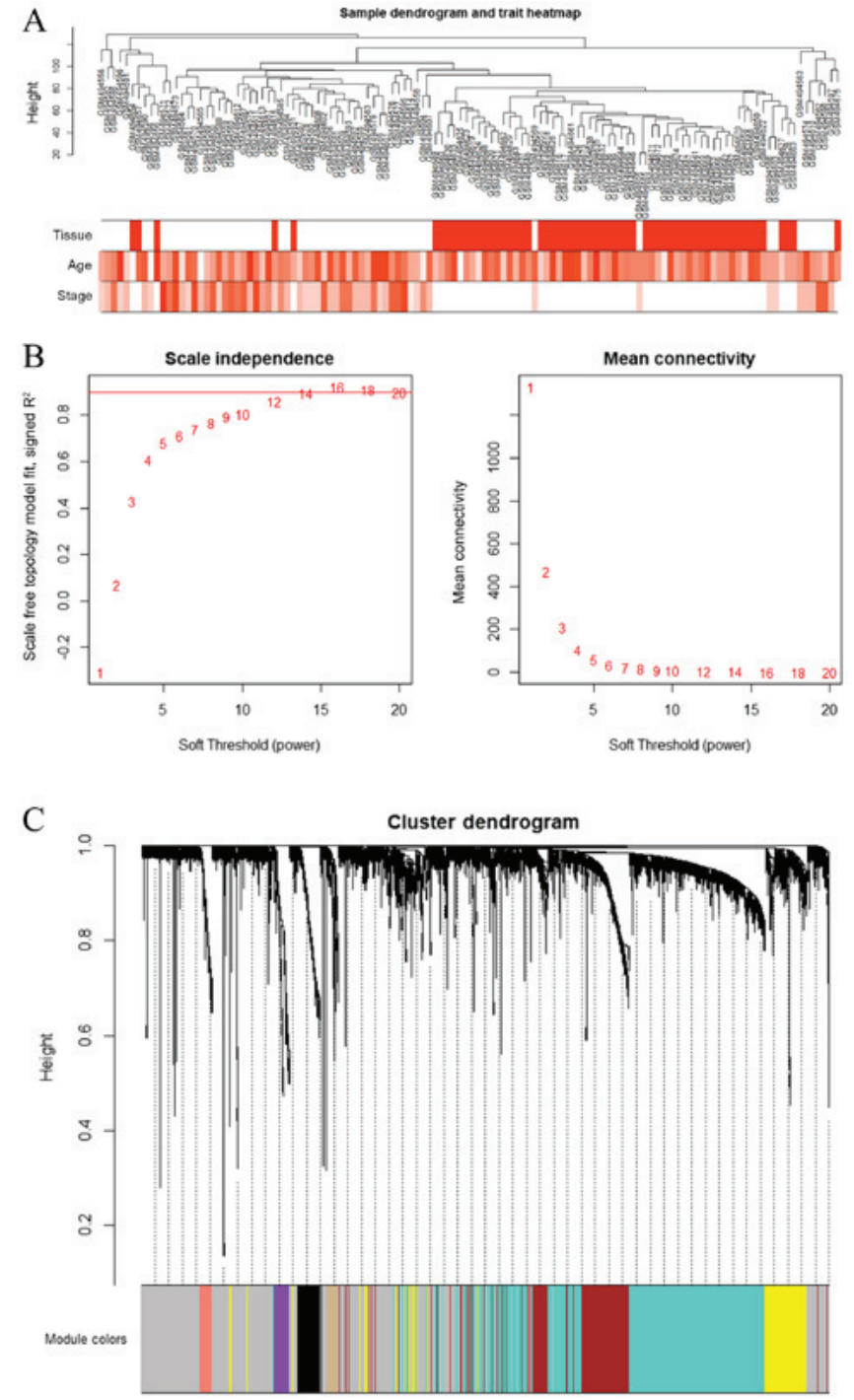

Figure 1. Weighted gene co-expression network construction and gene module recognition. (A) A clustering diagram of gene expression data based on GSE19804, which contains 60 lung cancer samples and 60 normal samples. The darker the corresponding colour block below the cluster diagram, the larger value of the corresponding clinical information of the sample. (B) The scale-free fitting index of soft threshold power ( $\beta$ ), and 14 is the most suitable power value. (C) A tree map of GSE19804 gene cluster. Each branch in the figure represents a gene, and each colour below represents a co-expression module.

trypsin, centrifuged at $300 \mathrm{x}$ g for $5 \mathrm{~min}$ at room temperature, washed in PBS and suspended in $200 \mu 1$ buffer solution. Subsequently, $5 \mu$ l Annexin V-FITC (BD Biosciences) was added to the $195-\mu 1$ cell suspension. After full mixing and incubation at room temperature for $10 \mathrm{~min}$, the cells were washed with $200 \mu \mathrm{l}$ buffer solution and resuspended in $190 \mu \mathrm{l}$ buffer solution. Then, $10 \mu \mathrm{l}$ propidium iodide $(20 \mu \mathrm{g} / \mathrm{ml})$ was added for $30 \mathrm{~min}$ at $37^{\circ} \mathrm{C}$. The samples were analysed using am Accuri C6 flow cytometer with CFlow Plus analysis software version 1.5 (BD Biosciences)

Statistical analysis. All data were the results of three independent experiments, and expressed as the mean \pm standard deviation. SPSS 22.0 (IBM Corp.) was used for statistical analysis. Multiple comparisons of the means were performed using one-way analysis of variance followed by 

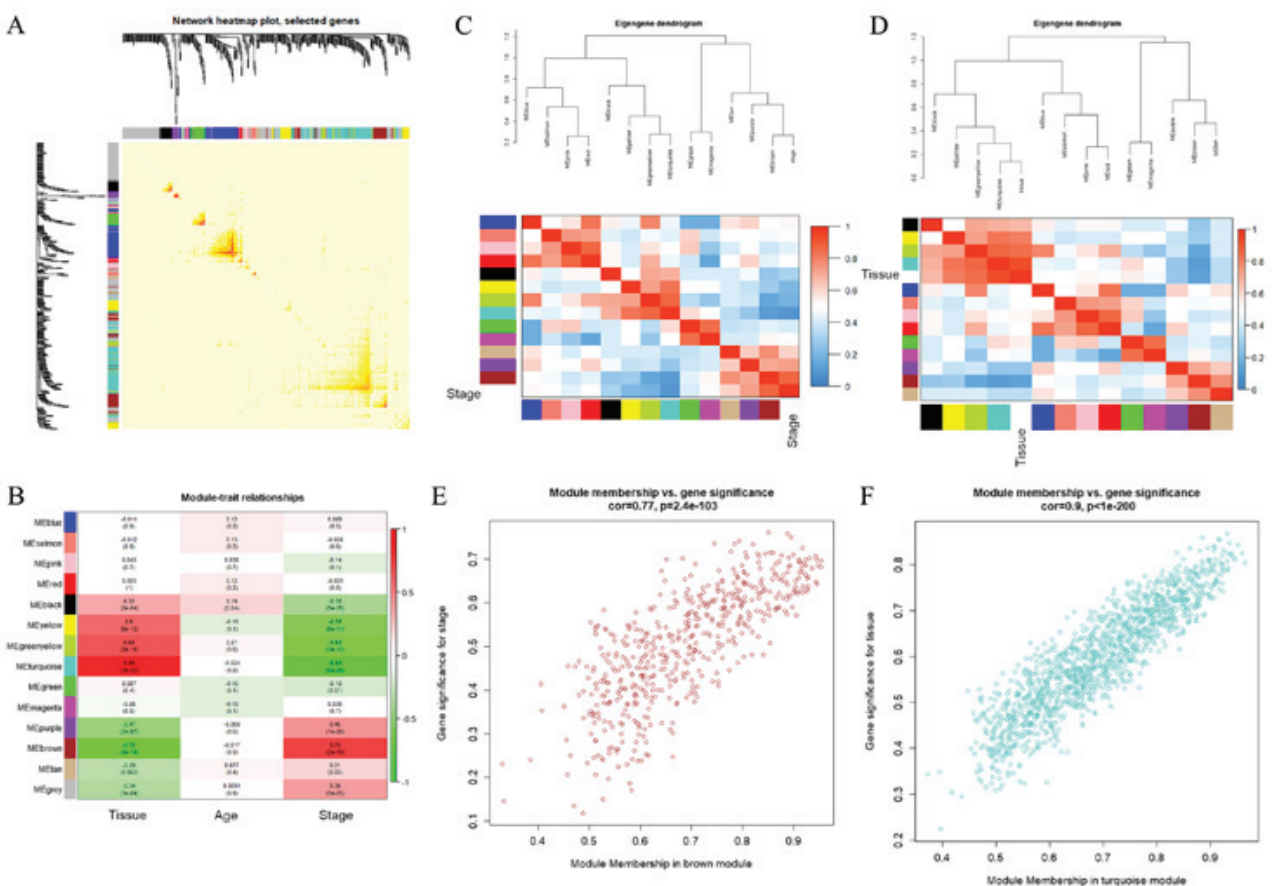

Figure 2. Screening hub modules related to clinical traits in lung cancer. (A) A relationship analysis diagram of the interaction of co-expressed genes. The different colours of the horizontal and vertical axes represent different modules. The yellow brightness in the middle indicates the degree of connection between the different modules. (B) A heat map of the correlation between module features and clinical information of lung cancer. The number above in each colour block is the correlation coefficient, and the P-value is in parentheses below. The colour of the colour block reflects the size of the correlation coefficient, referring to the legend on the right. (C) A hierarchical clustering diagram of modules. The brown module is most closely related to stage. (D) A hierarchical clustering diagram of modules. The turquoise module is most closely related to tissue. (E) The scatter plot of the brown module eigengenes. (F) A scatter plot of the turquoise module eigengenes.

Student-Newman-Keuls post hoc test. $\mathrm{P}<0.05$ was considered to indicate a statically significant difference.

\section{Results}

Acquisition of microarray data. GSE19804 raw data were downloaded from the GEO database. The Affymetrix Human Genome U133 Plus 2.0 Array platform annotation information was used to match probes and gene names. Ultimately, the present study obtained a total of 120 samples, including the expression data of 60 normal samples and 60 lung cancer samples, as well as their related clinical information (Table SI).

WGCNA construction and gene module recognition. The first $25 \%$ of variance genes in the GSE19804 chip data were used for cluster analysis through the WGCNA package. To ensure the reliability of the network structure, no outlier samples were included after calculation (Fig. 1A). The first $25 \%$ of the gene expression data were used to construct a WGCNA. The power value of 14 was selected (Fig. 1B), and 14 modules were generated (Fig. 1C), where the grey module was a gene that was not co-expressed.

The interaction between the 14 modules was analysed and a network heat map was generated, which demonstrated the relative independence between the modules (Fig. 2A). As presented in Fig. 2B, compared with other modules, the black, yellow, yellow-green and turquoise modules were positively correlated with tissue (having cancer or not) and negatively correlated with stage (cancer development stage). The purple and brown modules were negatively correlated with tissue (having cancer or not) and positively correlated with stage (stage of cancer development). In addition, the present study calculated the eigengenes of the module and clustered them according to their correlation with tissue. Among them, the brown module was most closely related to stage. Similar results were demonstrated by heat maps based on adjacencies (Fig. 2C and D). Therefore, it was determined that the turquoise module and the brown module were the modules most relevant to lung cancer. Fig. $2 \mathrm{E}$ and $\mathrm{F}$ illustrate the associations between the brown and turquoise modules and the genetic significance.

GO enrichment analysis and KEGG pathway analysis. The GO enrichment analysis and KEGG enrichment analysis of the brown module and turquoise module were performed using the $\mathrm{R}$ package clusterProfiler. $\mathrm{P}<0.05$ was defined as a significant result of enrichment analysis. The results of the enrichment analysis were closely associated with lung cancer, which demonstrated the correctness of the present analysis results, as presented in Fig. 3A-D and Tables SII-V.

Network analysis identifies hub nodes. The present study conducted a visualized analysis of all the modules in Cytoscape, as presented in Fig. 4A, where the interrelationships between the modules are shown. The turquoise module and brown module were imported into Cytoscape for topology analysis. The topological parameters of all nodes in the two module networks (Tables SVI and SVII) were calculated and the top 30 nodes of each module were screened (33), which were selected to draw the network diagram, as presented in Fig. 4B and C. A total of 60 nodes were used as candidate key nodes for subsequent analysis. 

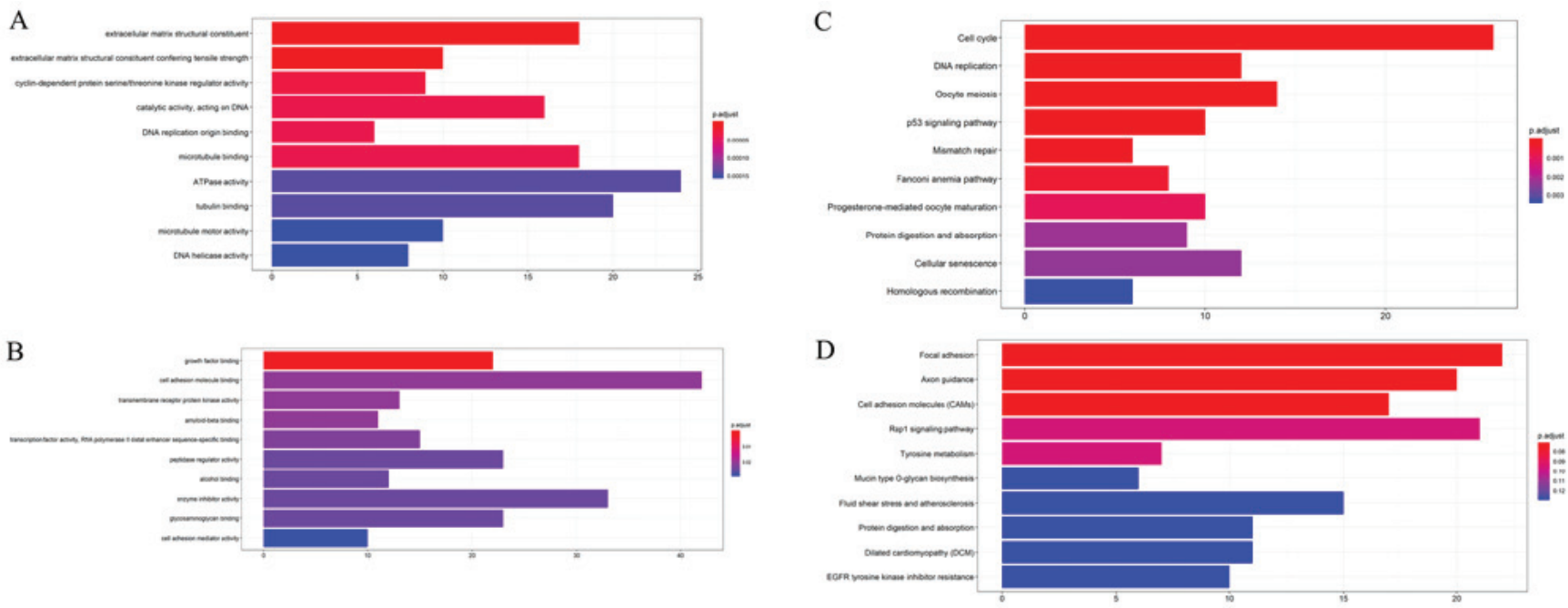

Figure 3. GO enrichment analysis and KEGG pathway analysis of modular genes. (A) A GO enrichment analysis diagram of genes in the brown module. (B) A GO enrichment analysis map of genes in the turquoise module. (C) KEGG analysis of genes in the brown module. (D) KEGG analysis of genes in the turquoise module. The x-axis represents the number of genes, and the y-axis represents the GO term or KEGG pathway. GO, Gene Ontology; KEGG, Kyoto Encyclopaedia of Genes and Genomes.
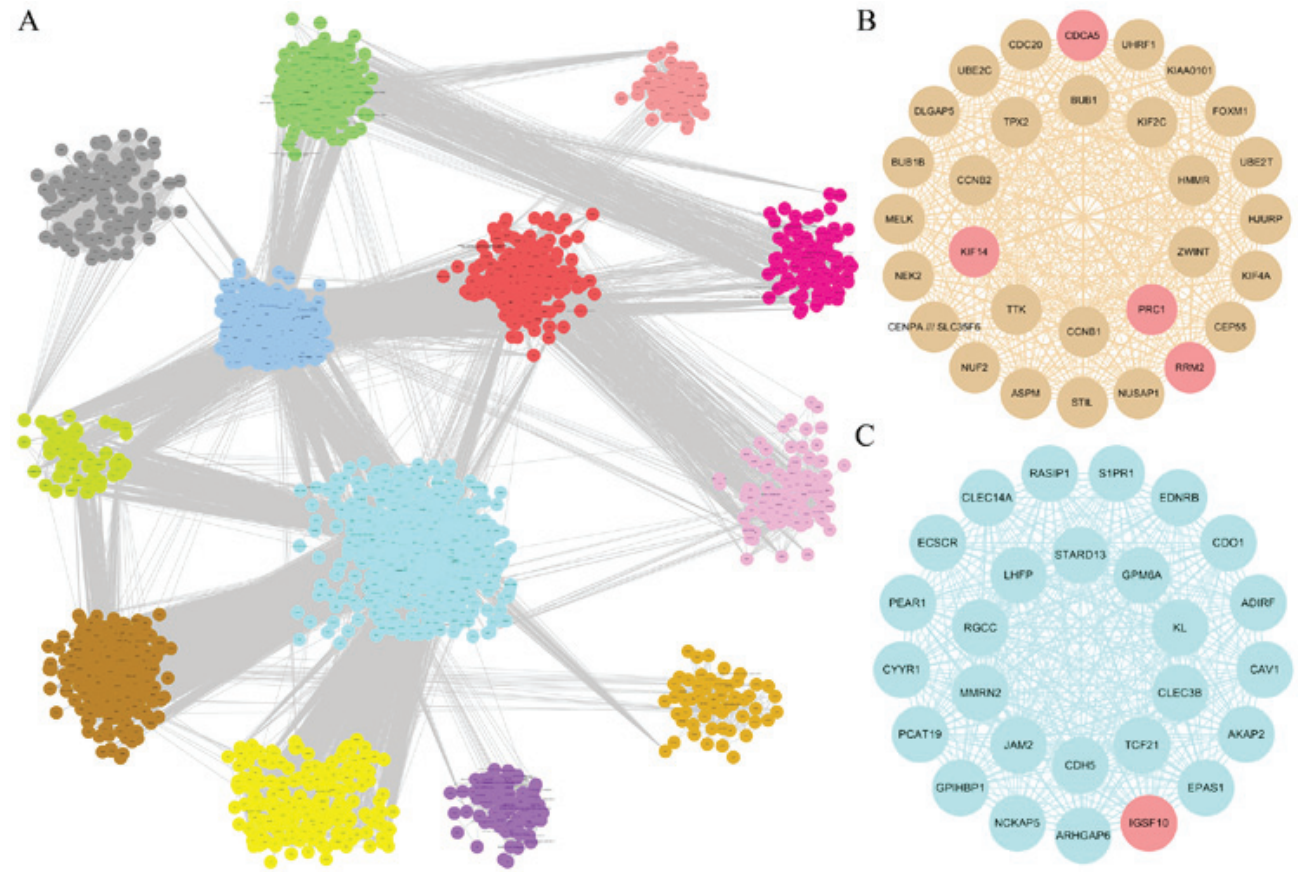

Figure 4. Screening hub nodes in the network module. (A) A co-expression network diagram based on GSE19804 data. The colour of the nodes represents the module to which they belong. The grey connection is the co-expression relationship between the nodes. (B) In the brown module, the brown nodes are the top 30 nodes and the red nodes are the core nodes. The brown connections are the co-expression relationships between the nodes. (C) The turquoise nodes are the top 30 nodes, and the red node is the core node. The turquoise connections are the co-expression relationships between the nodes.

Survival analysis of the hub genes. GEPIA was used to analyse the overall survival and $\mathrm{P}<0.05$ was considered to be statistically significant. Further survival analysis was performed on a total of 60 key genes selected above. A total of 5 genes were significantly associated with the prognosis of patients $(\mathrm{P}<0.05)$, including the IGSF10 gene of the turquoise module, and the ribonucleotide reductase regulatory subunit M2 (RRM2), protein regulator of cytokinesis 1 (PRC1), kinesin family member (KIF)14 and KIF2C genes of the brown module (Fig. 5). As the expression levels of RRM2, PRC1, KIF14 and $\mathrm{KIF} 2 \mathrm{C}$ in the brown module increased, the total survival time was significantly reduced. By contrast, as the expression of IGSF10 in the turquoise module decreased, the total survival time was significantly decreased.

Dataset validation. Lung adenocarcinoma and lung squamous cell carcinoma data from TCGA database were used to validate the screened key genes, as presented in Fig. 6. The expression of IGSF10 from the turquoise module was significantly lower in patients compared with normal controls. The expression levels of RRM2, PRC1, KIF14 and KIF2C from the brown module were higher in patients compared with 

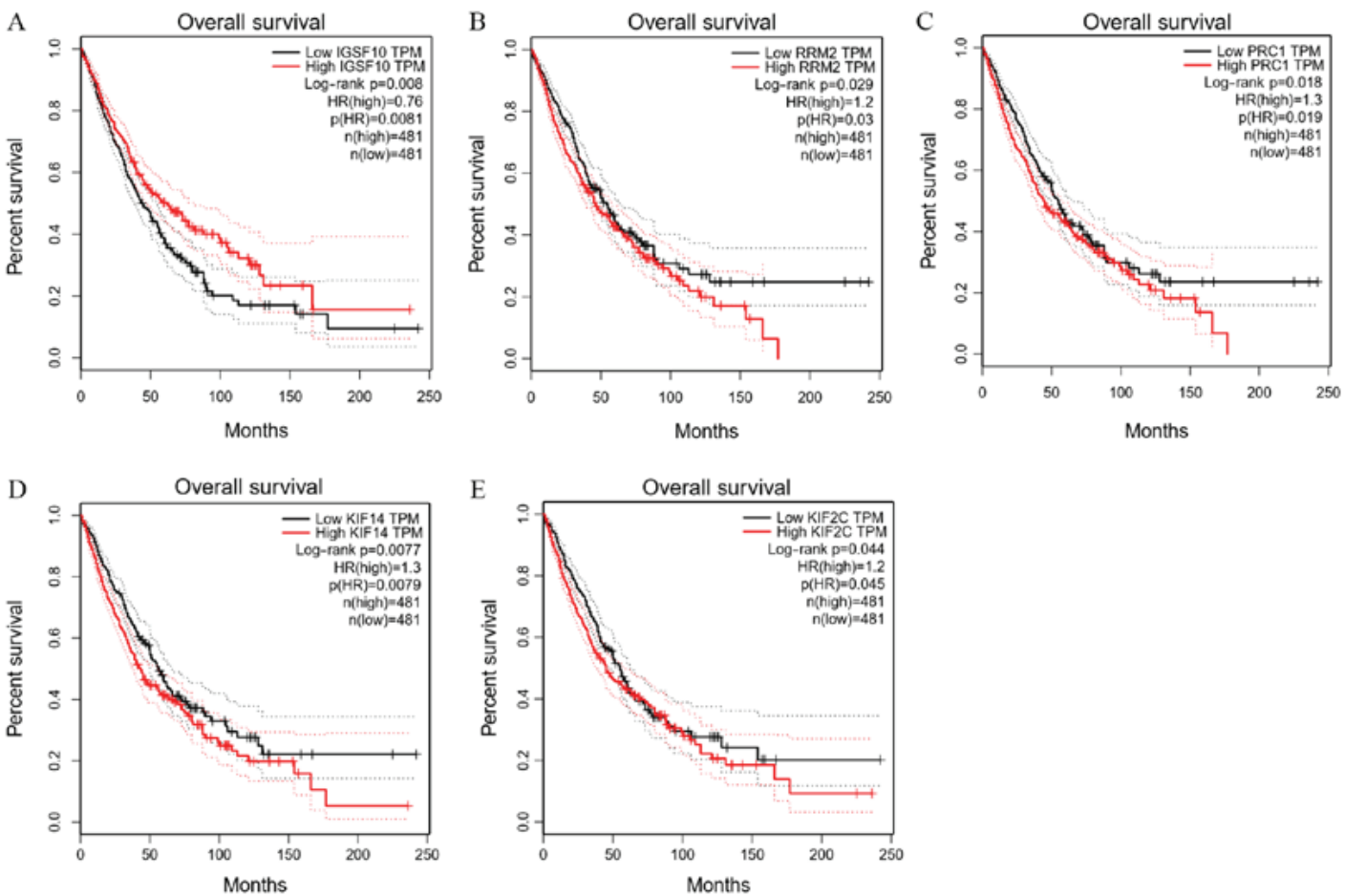

Figure 5. Survival analysis of the core genes. (A) The survival curve of IGSF10. (B) The survival curve of RRM2. (C) The survival curve of PRC1. (D) The survival curve of KIF1. (E) The survival curve of KIF2C. HR, hazard ratio; IGSF10, immunoglobulin superfamily member 10; RRM2, ribonucleotide reductase regulatory subunit M2; $\mathrm{PRC1}$, protein regulator of cytokinesis 1; KIF, kinesin family member.

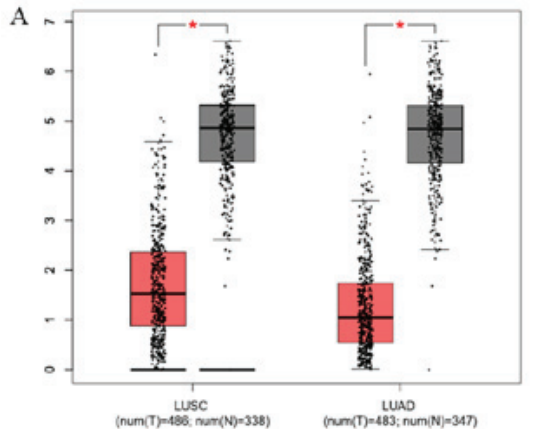

IGSF10

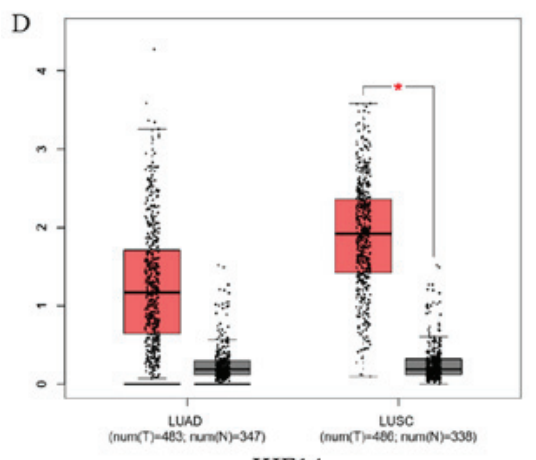

KIF14

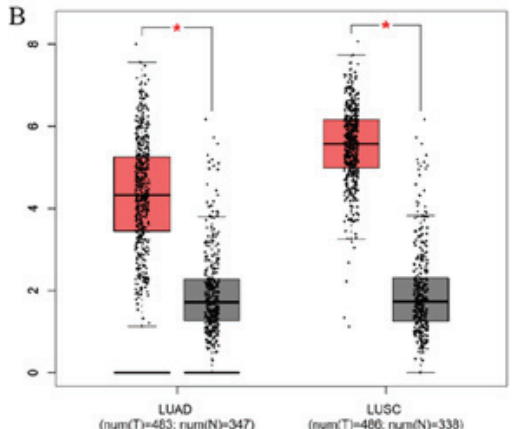

RRM2

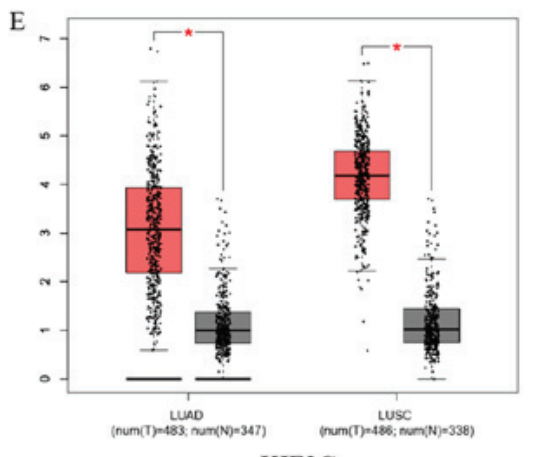

KIF2C

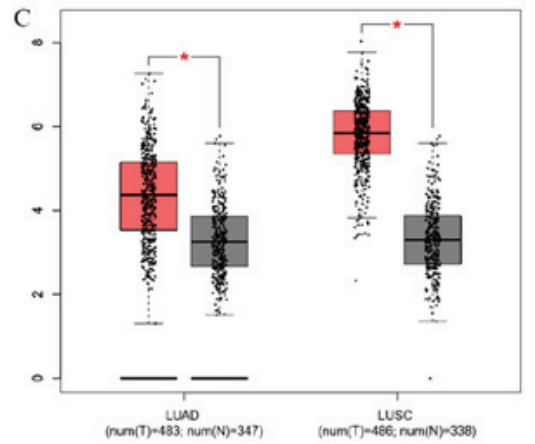

PRC1

Figure 6. Analysis of differential expression in normal controls and patients with cancer based on core genes of The Cancer Genome Atlas database. (A) The differential expression of IGSF10. (B) The differential expression of RRM2. (C) The differential expression of PRC1. (D) The differential expression of KIF14. (E) The differential expression of KIF2C. Red indicates high expression and grey indicates low expression. " $\mathrm{P}<0.05$. LUSC, lung squamous cell carcinoma; LUAD, lung adenocarcinoma; IGSF10, immunoglobulin superfamily member 10; RRM2, ribonucleotide reductase regulatory subunit M2; PRC1, protein regulator of cytokinesis 1 ; KIF, kinesin family member.

normal controls. These results were consistent with those of the survival analysis, except that no significant difference was identified in KIF14 expression between patients with lung adenocarcinoma and normal controls. 
A

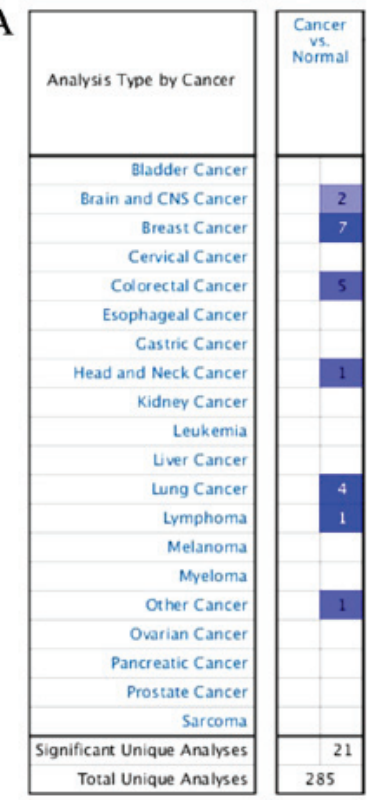

B

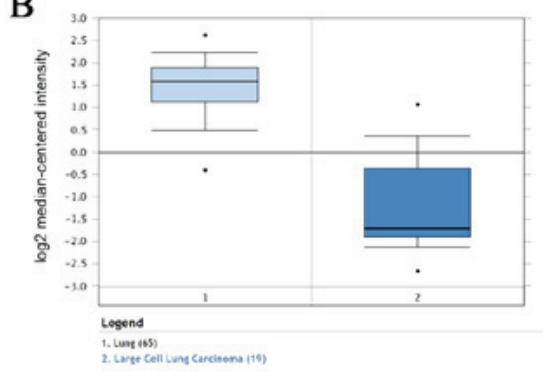

D

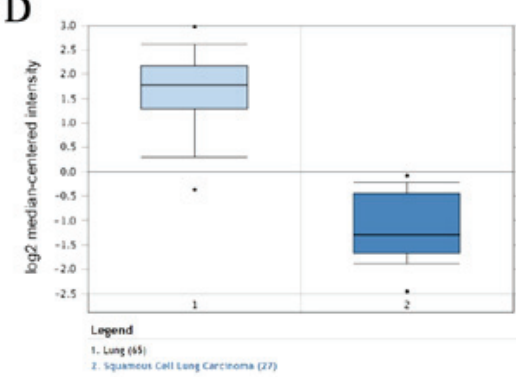

C

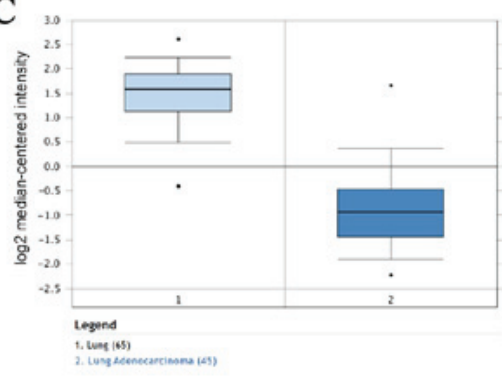

E

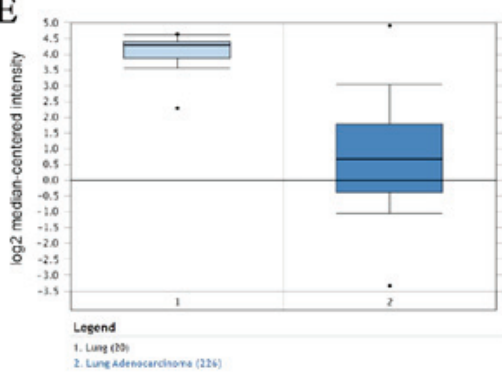

Figure 7. Expression of IGSF10 in different types of cancer in the Oncomine database. (A) Expression of IGSF10 in different cancer types based on the Oncomine platform. (B) Expression of IGSF10 in samples of normal and large cell carcinoma in the Hou Lung dataset. (C) Expression of IGSF10 in samples of normal and adenocarcinoma in the Hou Lung dataset. (D) Expression of IGSF10 in samples of normal and squamous cell lung carcinoma in the Hou Lung dataset. (E) Expression of IGSF10 in samples of normal and lung adenocarcinoma in the Okayama Lung dataset. IGSF10, immunoglobulin superfamily member 10 .
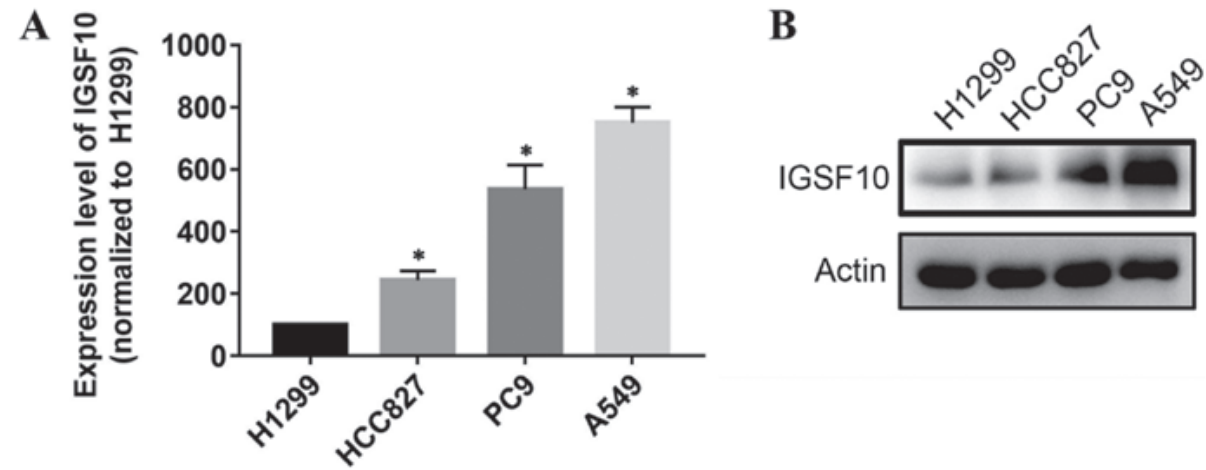

Figure 8. RT-qPCR and western blotting validation of the expression level of IGSF10 in lung cancer cell lines. (A) RT-qPCR detection of mRNA expression of IGSF10 in four NSCLC cell lines. (B) Western blotting verified the protein expression level of IGSF10 in four NSCLC cell lines. *P<0.05. IGSF10, immunoglobulin superfamily member 10; RT-qPCR, reverse transcription-quantitative polymerase chain reaction; NSCLC, non-small cell lung cancer.

Expression of IGSF10 in different types of cancer in the Oncomine database. The expression of IGSF10 in normal controls and in different types of lung cancer was compared in the Oncomine database. As presented in Fig. 7A, the expression of IGSF10 was low in brain and CNS cancer, breast cancer, colorectal cancer, head and neck cancer, lung cancer and lymphoma, The expression of IGSF10 in the Hou Lung and Okayama Lung datasets was downregulated, as presented in Fig. 7B-E.

Knockdown of IGSF10 in vitro can promote the proliferation of lung cancer cells. To select the appropriate cell model for the following experiments, the present study first compared the expression levels of IGSF10 in lung adenocarcinoma cells (A549, H1299, HCC827 and PC9) (Fig. 8). A549 and PC9 cell lines were selected for further analysis as the expression levels of IGSF10 in these cells were the highest. The reduction efficiency was evaluated by siRNA knockdown of IGSF10, followed by RT-qPCR and western blotting (Fig. 9). MTT experiments revealed that the proliferative ability of A549 and PC9 cells was significantly increased following IGSF10-knockdown (Fig. 10A). The colony formation experiments demonstrated that the number of colonies in the IGSF10-siRNA transfection group was significantly higher compared with that in the NC-siRNA group (Fig. 10B). Ultimately, the effect of IGSF10 on apoptosis was evaluated by flow cytometry analysis. As shown in Fig. 10C, there was no significant difference in apoptosis between the IGSF10-siRNA transfection group and the NC-siRNA group. These results suggest that knockdown of IGSF10 significantly promoted the proliferation of lung cancer cells.

Knockdown of IGSF10 in vitro enhances the invasion, migration and adhesion of lung cancer cells. In addition, it 


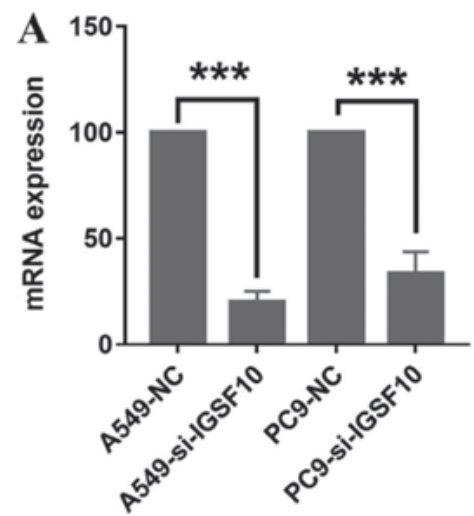

B

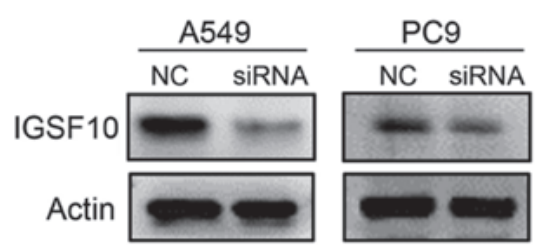

Figure 9. RT-qPCR and western blotting validation of the knockdown efficiency of IGSF10 siRNA. (A) RT-qPCR and (B) western blotting verified siRNA-mediated inhibition of IGSF10 expression in A549 and PC9 cells. ${ }^{* * *} \mathrm{P}<0.001$. RT-qPCR, reverse transcription-quantitative polymerase chain reaction; IGSF10, immunoglobulin superfamily member 10; si, small interfering; NC, negative control.

$\mathbf{A}$

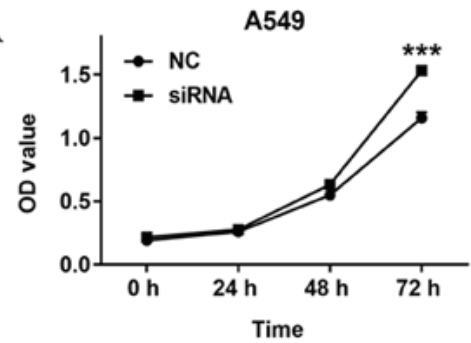

B

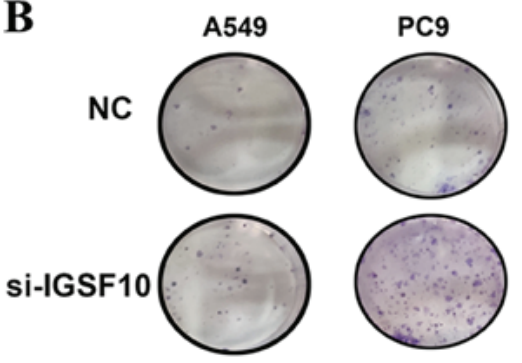

C

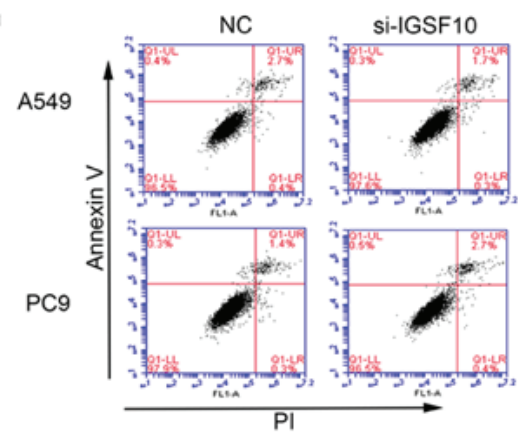

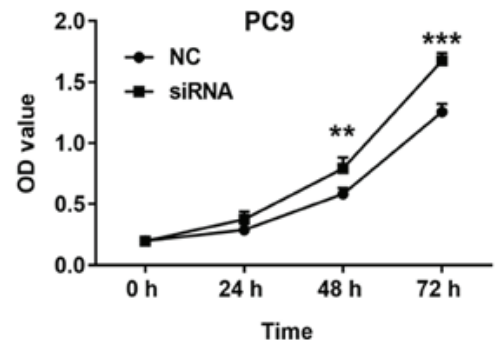
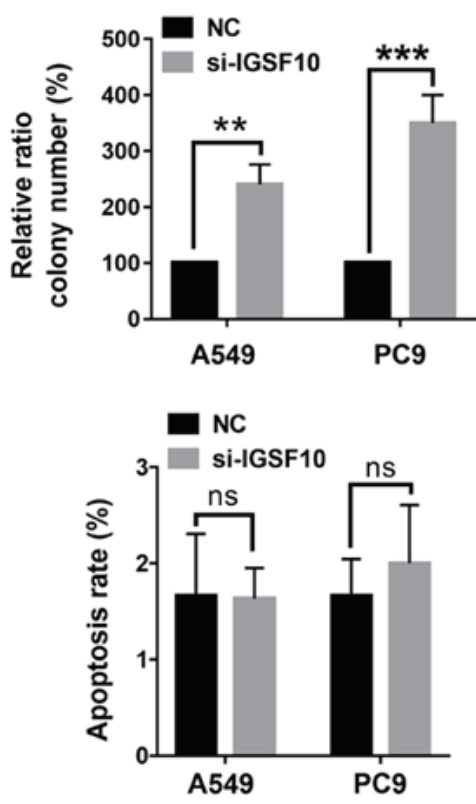

Figure 10. Effect of IGSF10-knockdown on the proliferation of lung cancer cells. (A) MTT assay and (B) colony formation experiment detected the changes in proliferation ability of A549 and PC9 cells after IGSF10-siRNA transfection. Magnification, $\mathrm{x} 40$. (C) Apoptosis was detected by flow cytometry. ${ }^{* *} \mathrm{P}<0.01$, ${ }_{* * * * *} \mathrm{P}<0.001$ vs. NC. ns, not significant; NC, negative control; IGSF10, immunoglobulin superfamily member 10; si, small interfering; PI, propidium iodide; OD, optical density.

was investigated whether IGSF10 can affect the invasion and migration of lung cancer cells. Wound healing experiments revealed that the knockdown of IGSF10 significantly increased the migration ability of A549 and PC9 cells (Fig. 11A). This result was further validated by Transwell and Matrigel experiments in which the migration and invasion ability of the IGSF10 siRNA transfection group was significantly enhanced
(Fig. 11B). In Fig. 11C, the adhesion experiment confirmed that the adhesion between cells and the matrix was significantly enhanced following IGSF10-knockdown.

Integrin- $\beta 1 / F A K$ pathway is activated following knockout of IGSF10 in vitro. GSEA demonstrated that IGSF10 was significantly associated with 'ECM receptor interaction' and 'Focal 


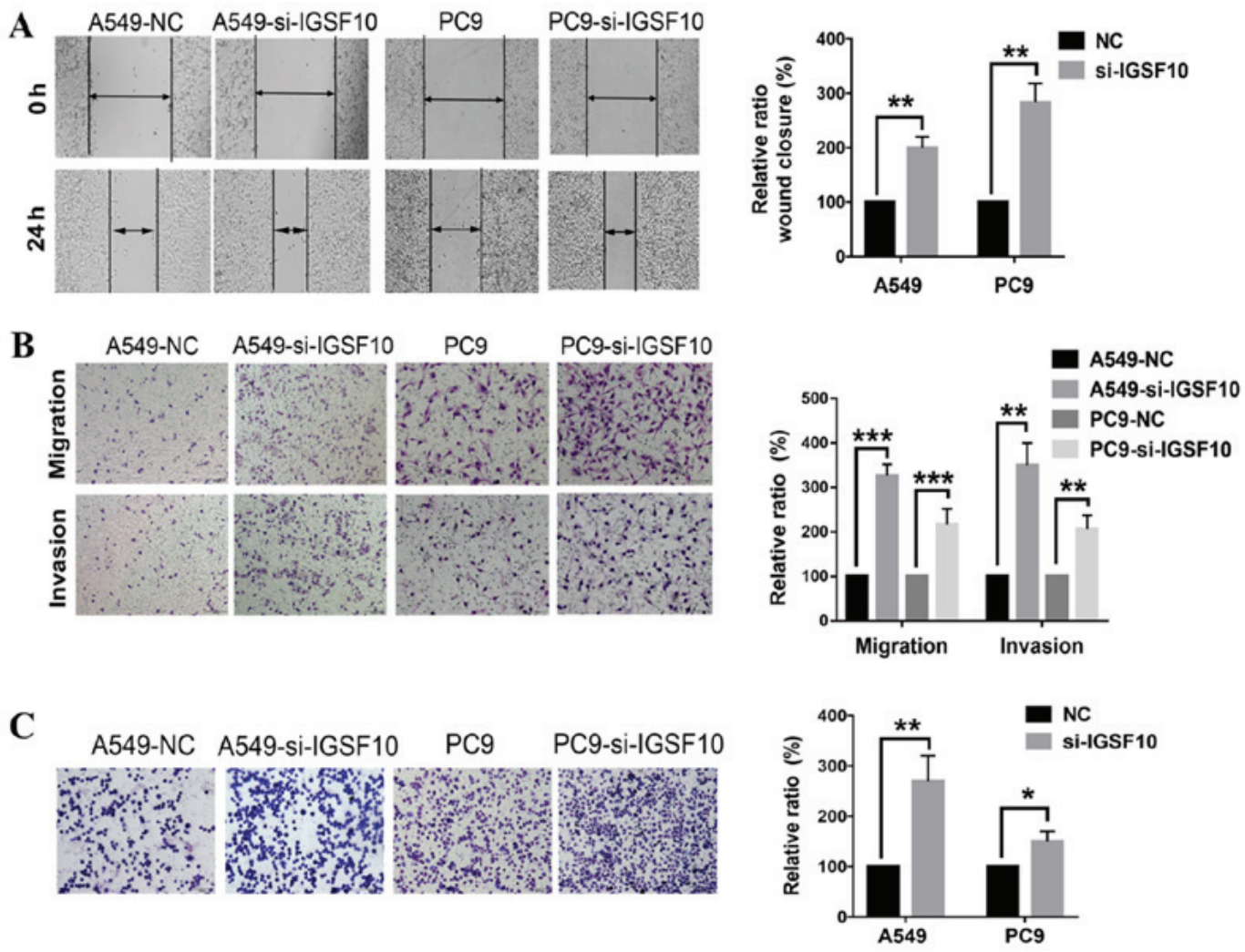

Figure 11. Effects of IGSF10 on invasion, migration and adhesion of lung cancer cells. (A) Scratch test showed that the knockdown of IGSF10 could increase the migration ability of A549 and PC9 cells. (B) Transwell experiment was performed $48 \mathrm{~h}$ after IGSF10-siRNA transfection. The number of cells on the Transwell membrane was compared. The results showed that the ability of migration and invasion was significantly upregulated. (C) The adhesion capacity between A549 and PC9 cells and the matrix significantly increased following knockdown of IGSF10. Magnification, $x 200 .{ }^{*} \mathrm{P}<0.05,{ }^{* *} \mathrm{P}<0.01,{ }^{* * *} \mathrm{P}<0.001 . \mathrm{NC}$, negative control; IGSF10, immunoglobulin superfamily member 10; si, small interfering;

A

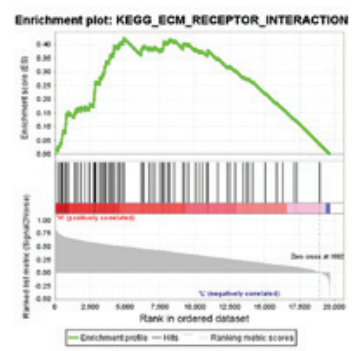

$\mathrm{C}$

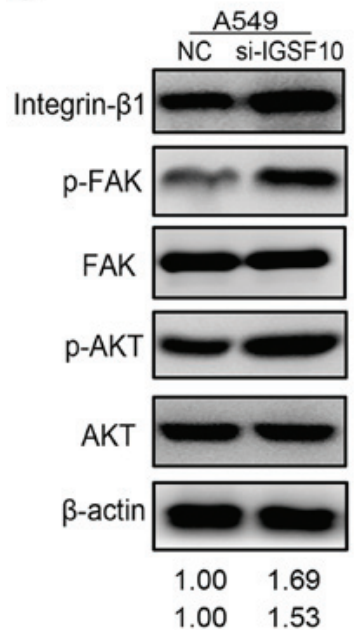

$\mathrm{B}$
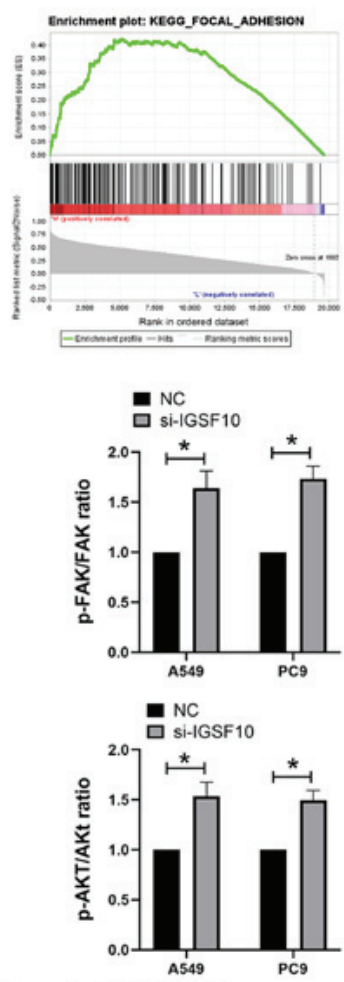

1.001 .75 ratios of $p$-FAK/FAK

1.001 .48 ratios of $\mathrm{p}-\mathrm{AKT} / \mathrm{AKT}$

Figure 12. Activation of the integrin- $\beta 1 /$ FAK pathway after IGSF10-knockdown. (A) KEGG_ECM_RECEPTOR_INTERACTION. (B) KEGG_FOCAL_ ADHESION. (C) The protein expression level changes of integrin- $\beta 1$, p-FAK, p-AKT, FAK and AKT were detected by western blotting. FAK, focal adhesion kinase; p, phosphorylated; si, small interfering; NC, negative control; IGSF10, immunoglobulin superfamily member 10. 
adhesion'. Therefore, these results were verified by western blotting.

Integrins are located on the surface of the cell membrane and are cross-membrane receptors that promote the adhesion of the cell-extracellular matrix. The integrin family plays an important role in cell adhesion $(34,35)$. The present study aimed to investigate the relationship between IGSF10 and the integrin pathway in lung cancer. As presented in Fig. 12, the protein expression levels of integrin- $\beta 1, \mathrm{p}-\mathrm{FAK}$ and $\mathrm{p}-\mathrm{AKT}$ were significantly upregulated following the knockout of IGSF10 in A549 and PC9 cells. The protein expression levels of FAK and AKT did not change significantly. These results showed that after knocking out IGSF10, the activation of the integrin- $\beta 1 /$ FAK pathway in NSCLC cells may promote the malignant phenotype of tumour cells (Fig. 12).

\section{Discussion}

The occurrence and development of lung cancer is similar to that of most tumours, which is a multi-stage development process with multiple genes and multiple factors $(36,37)$. An in-depth understanding of the molecular mechanism of the occurrence and development of lung cancer is conducive to developing effective targeted therapies, while also providing clues for the early diagnosis of lung cancer (38). The present study used WGCNA to investigate biomarkers associated with the pathogenesis of lung cancer. A total of 14 gene modules were divided in the WGCNA network based on the GSE19804 dataset, of which two modules were significantly correlated with lung cancer (both $\mathrm{P}<0.001$ ). Five core genes, including IGSF10, RRM2, PRC1, KIF14 and KIF2C, were obtained from these two modules. Among them, there have been reports on the mechanisms of RRM2, PRC1, KIF14 and KIF2C in lung cancer.

RRM2 is often highly active in lung cancer cells (39), and its expression level is associated with tumour cell invasion, tumour angiogenesis, tumour metastasis and the prognosis of patients (40-43). Therefore, RRM2 is closely related to the biological behaviour and metastasis potential of malignant tumours.

The PRC1 gene causes disorders in the body in a specific carcinogenic pattern that is associated with the occurrence of a variety of human cancer types (44). The results of gene expression analysis have demonstrated that the expression of PRC1 is upregulated in numerous types of clinical cancer, including colon cancer, non-small cell lung cancer, pancreatic cancer and breast cancer (45-47). This suggests that PRC1 may be an important tumour-promoting gene, playing an important role in the occurrence and development of numerous malignant tumours. Chen et al (48) found that the high expression of PRC1 can promote the proliferation and metastasis of hepatocellular carcinoma (HCC) cells through a mutual regulation of the Wnt/ $\beta$-catenin signalling pathway, thus promoting the early recurrence and poor prognosis of HCC. Tang et al (49) suggested that PRC1 may be associated with poor prognosis in non-small cell lung cancer. At the same time, the expression level of PRC1 in the cancer tissues of patients with non-small cell lung cancer after chemotherapy was lower than that before chemotherapy. This suggests that under certain conditions, the mRNA level of PRC1 can not only predict the prognosis of patients but may also be used as an important reference index to evaluate the effect of tumour treatment.

Hung et al (50) studied the expression levels of KIF14 in 122 cases of lung adenocarcinoma and found that $\sim 30 \%$ of patients with lung adenocarcinoma exhibited a downregulation of KIF14 expression. In addition, the decreased expression of KIF14 was significantly correlated with the overall survival rate of patients with lung cancer. Corson et al (51) found that the expression level of KIF14 is significantly associated with the disease-free survival rate and overall survival rate, and can be used as a prognostic marker of lung cancer.

Bai et al (52) analysed the microarray data of GSE31210 containing lung adenocarcinoma $(n=226)$ and normal lung tissue $(n=20)$ samples and found that the high expression of KIF2C was closely associated with the recurrence of lung adenocarcinoma and tumour stage. The overall survival rate of patients with lung adenocarcinoma with a high expression of KIF2C was significantly decreased.

Song et al (53) also obtained similar conclusions based on a differential gene expression analysis in GEO datasets.

At present, there are few studies on IGSF10 in the literature, and the mechanism related to lung cancer is unclear, warranting further study $(54,55)$. The present study used the Oncomine database to investigate the expression of IGSF10 in different cancer types, which revealed that the expression of IGSF10 was low in numerous types of cancer. In addition to low expression of IGSF10 in lung cancer, low expression was found in breast cancer, colon cancer and head and neck cancer. To clarify the mechanism of IGSF10 in lung cancer, the present study further examined the effect of IGSF10 on the proliferation of lung cancer cells, the adhesion between cells and the matrix, and the related metabolic pathways through cell biology experiments. The experimental results showed that knockout of IGSF10 significantly promoted the proliferation of lung cancer cells, enhanced the adhesion between cells and the matrix, and activated the integrin- $\beta 1 /$ FAK pathway, as demonstrated by an increase in the protein expression of integrin- $\beta 1, \mathrm{p}-\mathrm{FAK}$ and p-AKT. Integrin- $\beta 1$ is one of the subunits of integrin. The FAK-mediated signal transduction activated by integrin- $\beta 1$ plays an important role in this process. It regulates a variety of cellular functions, including apoptosis, cell proliferation, cell adhesion and migration by mediating tumour and basal membranes, tumour and host cell adhesion as well as signal transduction (56). Therefore, it plays an important role in the occurrence and metastasis of tumour cells (57). FAK is the mediator connecting integrin and downstream signal molecules in the integrin- $\beta 1 / F A K$ signalling pathway, which is at the intersection of multiple signal pathways. Activated FAK can further activate the FAK-AKT pathway, FAK-Ras-MAPK pathway, FAK-PI3K pathway, FAK-STAT pathway and other signalling pathways, thus controlling transcription, translation, the cell cycle, apoptosis and other biological effects $(58,59)$. Therefore, activation of the integrin- $\beta 1 /$ FAK pathway following IGSF10-knockout may be responsible for the promotion of cell proliferation, enhancement of adhesion between cells and the matrix, and the affect on the survival rate of patients.

In conclusion, the present study revealed that the biomarker IGSF10 is closely associated with lung cancer based on WGCNA. The possible mechanism and effects of 
IGSF10 on tumour cells were preliminarily investigated through biological experiments. Currently, there are a number or further analyses that are required. For example, the use of mRNA data to analyse lung cancer with high heterogeneity is inadequate, and combining these data with genome, proteome, methylation data and other multi-omics data for more in-depth research is necessary. In addition, with the advent of the high-throughput era, the construction of a more comprehensive bioinformatics database on lung cancer coupled with the expansion of the sample size will help to improve the accuracy of screening to explore potential gene biomarkers.

\section{Acknowledgements}

Not applicable.

\section{Funding}

This study was supported by grants from the National Natural Science Foundation of China (grant no. 81660549) and Natural Science Foundation of Guangxi (grant no. 2016GXNSFAA380276).

\section{Availability of data and materials}

The datasets used and/or analyzed during the present study are available from the corresponding author on reasonable request.

\section{Authors' contributions}

BL, YP and GQ designed the current study. BL, LL and YJ performed the experiments. BL, XL and $\mathrm{YH}$ analyzed and interpreted the data. BL wrote the manuscript. YP and GQ supervised the study. All authors read and approved the final version of the manuscript and agreed to be accountable for all aspects of the research in ensuring that the accuracy or integrity of any part of the work are appropriately investigated and resolved.

\section{Ethics approval and consent to participate}

Not applicable.

\section{Patient consent for publication}

Not applicable.

\section{Competing interests}

The authors declare that they have no competing interests.

\section{References}

1. Yang D, Dai R, Zhang Q and Fang P: Apatinib for heavily treated patients with non-small cell lung cancer: Report of a case series and literature review. Saudi J Biol Sci 25: 888-894, 2018.

2. Gobbi G, Donati B, Do Valle IF, Reggiani F, Torricelli F, Remondini D, Castellani G, Ambrosetti DC, Ciarrocchi A and Sancisi V: The Hippo pathway modulates resistance to BET proteins inhibitors in lung cancer cells. Oncogene 38: 6801-6817, 2019.
3. Pan J: Dabrafenib Plus Trametinib for BRAF V600E-Mutant Non-small Cell Lung Cancer: A Patient Case Report. Clin Drug Investig 39: 1003-1007, 2019.

4. Liu Y, Xiong ZC, Sun X, Sun L, Zhang SL, Ma JT and Han CB: Impact of apatinib in combination with osimertinib on EGFR T790M-positive lung adenocarcinoma. Transl Cancer Res 8: 2151-2163, 2019.

5. Ito T, Kumagai Y, Itano K, Maruyama T, Tamura K, Kawasaki S, Suzuki T and Murakami Y: Mathematical analysis of gefitinib resistance of lung adenocarcinoma caused by MET amplification. Biochem Biophys Res Commun 511: 544-550, 2019.

6. Nelson AW, Schrock AB, Pavlick DC, Ali SM, Atkinson EC and Chachoua A: Novel SPECC1L-MET Fusion Detected in Circulating Tumor DNA in a Patient with Lung Adenocarcinoma following Treatment with Erlotinib and Osimertinib. J Thorac Oncol 14: e27-e29, 2019.

7. Nakasuka T, Ichihara E, Makimoto G, Maeda Y and Kiura K: Primary Resistance to Alectinib Was Lost after Bevacizumab Combined Chemotherapy in ALK-Rearranged Lung Adenocarcinoma. J Thorac Oncol 14: e168-e169, 2019.

8. Wu K, Li J, Qi Y, Zhang C, Zhu D, Liu D and Zhao S: SNHG14 confers gefitinib resistance in non-small cell lung cancer by up-regulating ABCB1 via sponging miR-206-3p. Biomed Pharmacother 116: 108995, 2019.

9. Gu Y, Zhu X, Cao B, Wu X, Tong X, Shao YW and Liang L: Transformation to small cell lung cancer and activation of KRAS during long-term erlotinib maintenance in a patient with non-small cell lung cancer: A case report. Oncol Lett 17: 5219-5223, 2019

10. Saito H, Fukuhara T, Furuya N, Watanabe K, Sugawara S, Iwasawa S, Tsunezuka Y, Yamaguchi O, Okada M, Yoshimori K, et al: Erlotinib plus bevacizumab versus erlotinib alone in patients with EGFR-positive advanced non-squamous non-small-cell lung cancer (NEJ026): Interim analysis of an open-label, randomised, multicentre, phase 3 trial. Lancet Oncol 20: 625-635, 2019.

11. Wang J, Sheng Z and Cai Y: Effects of microRNA-513b on cell proliferation, apoptosis, invasion, and migration by targeting HMGB3 through regulation of mTOR signaling pathway in non-small-cell lung cancer. J Cell Physiol 234: 10934-10941, 2019.

12. Qiu BQ, Zhang PF, Xiong D, Xu JJ, Long X, Zhu SQ, Ye XD, Wu Y, Pei X, Zhang XM and Wu YB: CircRNA fibroblast growth factor receptor 3 promotes tumor progression in non-small cell lung cancer by regulating Galectin-1-AKT/ERK1/2 signaling. J Cell Physiol 234: 11256-11264, 2019.

13. Braicu C, Zimta A-A, Harangus A, Iurca I, Irimie A, Coza O and Berindan-Neagoe I: The function of non-coding RNAs in lung cancer tumorigenesis. Cancers (Basel) 11: 605, 2019.

14. Lukas TJ, Mirzoeva S, Slomczynska U and Watterson DM: Identification of novel classes of protein kinase inhibitors using combinatorial peptide chemistry based on functional genomics knowledge. J Med Chem 42: 910-919, 1999.

15. Kellner U, Steinert R, Seibert V, Heim S, Kellner A, Schulz HU, Roessner A, Krüger S and Reymond M: Epithelial cell preparation for proteomic and transcriptomic analysis in human pancreatic tissue. Pathol Res Pract 200: 155-163, 2004.

16. Baylin SB and Jones PA: A decade of exploring the cancer epigenome - biological and translational implications. Nat Rev Cancer 11: 726-734, 2011.

17. Zhang C, Peng L, Zhang Y, Liu Z, Li W, Chen S and Li G: The identification of key genes and pathways in hepatocellular carcinoma by bioinformatics analysis of high-throughput data. Med Oncol 34: 101, 2017.

18. Lu X, Lu J, Liao B, Li X, Qian X and Li K: Driver pattern identification over the gene co-expression of drug response in ovarian cancer by integrating high throughput genomics data. Sci Rep 7: 16188, 2017.

19. Busch R, Qiu W, Lasky-Su J, Morrow J, Criner G and DeMeo D: Differential DNA methylation marks and gene comethylation of COPD in African-Americans with COPD exacerbations. Respir Res 17: 143, 2016.

20. Pei G, Chen L and Zhang W: WGCNA application to proteomic and metabolomic data analysis. In: Methods in enzymology. Vol 585. Elsevier, pp135-158, 2017.

21. Langfelder P and Horvath S: WGCNA: An R package for weighted correlation network analysis. BMC Bioinformatics 9: $559,2008$.

22. Sun Q, Zhang W, Wang L, Guo F, Song D, Zhang Q, Zhang D, Fan Y and Wang J: Hypermethylated CD36 gene affected the progression of lung cancer. Gene 678: 395-406, 2018. 
23. An Y, Zhang Q, Li X, Wang Z, Li Y and Tang X: Upregulated microRNA miR-21 promotes the progression of lung adenocarcinoma through inhibition of KIBRA and the Hippo signaling pathway. Biomed Pharmacother 108: 1845-1855, 2018.

24. Lu TP, Tsai MH, Lee JM, Hsu CP, Chen PC, Lin CW, Shih JY Yang PC, Hsiao CK, Lai LC, et al: Identification of a nove biomarker, SEMA5A, for non-small cell lung carcinoma in nonsmoking women. Cancer Epidemiol Biomarkers Prev 19: 2590-2597, 2010.

25. He J, Hu Y, Hu M and Li B: Development of PD-1/PD-L1 Pathway in Tumor Immune Microenvironment and Treatment for Non-Small Cell Lung Cancer. Sci Rep 5: 13110, 2015.

26. Nakamura H, Ando K, Shinmyo T, Morita K, Mochizuki A, Kurimoto $\mathrm{N}$ and Tatsunami S: Female gender is an independent prognostic factor in non-small-cell lung cancer: A meta-analysis. Ann Thorac Cardiovasc Surg 17: 469-480, 2011

27. Matsuo K, Ito H, Yatabe Y, Hiraki A, Hirose K, Wakai K, Kosaka T, Suzuki T, Tajima K and Mitsudomi T: Risk factors differ for non-small-cell lung cancers with and without EGFR mutation: Assessment of smoking and sex by a case-control study in Japanese. Cancer Sci 98: 96-101, 2007.

28. Tang Z, Li C, Kang B, Gao G, Li C and Zhang Z: GEPIA: A web server for cancer and normal gene expression profiling and interactive analyses. Nucleic Acids Res 45 (W1): W98-W102, 2017

29. Hou J, Aerts J, den Hamer B, van Ijcken W, den Bakker M, Riegman P, van der Leest C, van der Spek P, Foekens JA, Hoogsteden HC, et al: Gene expression-based classification of non-small cell lung carcinomas and survival prediction. PLoS One 5: e10312, 2010.

30. Okayama H, Kohno T, Ishii Y, Shimada Y, Shiraishi K, Iwakawa R, Furuta K, Tsuta K, Shibata T, Yamamoto S, et al: Identification of genes upregulated in ALK-positive and EGFR/KRAS/ALK-negative lung adenocarcinomas. Cancer Res 72: 100-111, 2012

31. Welinder C and Ekblad L: Coomassie staining as loading control in Western blot analysis. J Proteome Res 10: 1416-1419, 2011.

32. Dunning K and Safo AO: The ultimate Wright-Giemsa stain: 60 years in the making. Biotech Histochem 86: 69-75, 2011.

33. Zhu W, Chen X, Ning L and Jin K: Network Analysis Reveals TNF as a Major Hub of Reactive Inflammation Following Spinal Cord Injury. Sci Rep 9: 928, 2019.

34. Cooper J and Giancotti FG: Integrin Signaling in Cancer: Mechanotransduction, Stemness, Epithelial Plasticity, and Therapeutic Resistance. Cancer Cell 35: 347-367, 2019.

35. Hamidi H and Ivaska J: Every step of the way: Integrins in cancer progression and metastasis. Nat Rev Cancer 18: 533-548, 2018.

36. Scarpa A, Sikora K, Fassan M, Rachiglio AM, Cappellesso R, Antonello D, Amato E, Mafficini A, Lambiase M, Esposito C, et al: Molecular typing of lung adenocarcinoma on cytological samples using a multigene next generation sequencing panel. PLoS One 8: e80478, 2013.

37. Tessema M, Yingling CM, Liu Y, Tellez CS, Van Neste L, Baylin SS and Belinsky SA: Genome-wide unmasking of epigenetically silenced genes in lung adenocarcinoma from smokers and never smokers. Carcinogenesis 35: 1248-1257, 2014.

38. Hamidaddin MA, AlRabiah H and Darwish IA: Development and comparative evaluation of two immunoassay platforms for bioanalysis of crizotinib: A potent drug used for the treatment of non-small cell lung cancer. Talanta 201: 217-225, 2019.

39. Heidel JD, Liu JY, Yen Y, Zhou B, Heale BS, Rossi JJ, Bartlett DW and Davis ME: Potent siRNA inhibitors of ribonucleotide reductase subunit RRM2 reduce cell proliferation in vitro and in vivo. Clin Cancer Res 13: 2207-2215, 2007.

40. Duxbury MS and Whang EE: RRM2 induces NF-kappaBdependent MMP-9 activation and enhances cellular invasiveness Biochem Biophys Res Commun 354: 190-196, 2007.

41. Lundin D, Berggren G, Logan DT and Sjöberg BM: The origin and evolution of ribonucleotide reduction. Life (Basel) 5 604-636, 2015

42. Li Y, Wang Z, Tang L, Hu R, Huang L and Ding J: RRM2 overexpression in glioblastoma enhances the proliferation and invasion of cancer cells. Int J Clin Exp Pathol 9: 11623-11630, 2016.
43. Chen WX, Yang LG, Xu LY, Cheng L, Qian Q, Sun L and Zhu YL: Bioinformatics analysis revealing prognostic significance of RRM2 gene in breast cancer. Biosci Rep 39: 39, 2019.

44. Federico A, Sepe R, Cozzolino F, Piccolo C, Iannone C, Iacobucci I, Pucci P, Monti M and Fusco A: The complex CBX7-PRMT1 has a critical role in regulating E-cadherin gene expression and cell migration. Biochim Biophys Acta Gene Regul Mech 1862: 509-521, 2019.

45. Yu F, Zhou C, Zeng H, Liu Y and Li S: BMI1 activates WNT signaling in colon cancer by negatively regulating the WNT antagonist IDAX. Biochem Biophys Res Commun 496: 468-474, 2018.

46. Ramaiah MJ and Vaishnave S: BMI1 and PTEN are key determinants of breast cancer therapy A plausible therapeutic target in breast cancer. Gene 678: 302-311, 2018.

47. Zhan P, Zhang B, Xi GM, Wu Y, Liu HB, Liu YF, Xu WJ, Zhu QQ, Cai F, Zhou ZJ, et al: PRC1 contributes to tumorigenesis of lung adenocarcinoma in association with the $\mathrm{Wnt} / \beta$-catenin signaling pathway. Mol Cancer 16: 108, 2017.

48. Chen J, Rajasekaran M, Xia H, Zhang X, Kong SN, Sekar K, Seshachalam VP, Deivasigamani A, Goh BK, Ooi LL, et al: The microtubule-associated protein PRC1 promotes early recurrence of hepatocellular carcinoma in association with the Wnt/ $\beta$-catenin signalling pathway. Gut 65: 1522-1534, 2016

49. Tang H, Xiao G, Behrens C, Schiller J, Allen J, Chow CW, Suraokar M, Corvalan A, Mao J, White MA, et al: A 12-gene set predicts survival benefits from adjuvant chemotherapy in non-small cell lung cancer patients. Clin Cancer Res 19: $1577-1586,2013$

50. Hung PF, Hong TM, Hsu YC, Chen HY, Chang YL, Wu CT, Chang GC, Jou YS, Pan SH and Yang PC: The motor protein KIF14 inhibits tumor growth and cancer metastasis in lung adenocarcinoma. PLoS One 8: e61664, 2013.

51. Corson TW, Zhu CQ, Lau SK, Shepherd FA, Tsao MS and Gallie BL: KIF14 messenger RNA expression is independently prognostic for outcome in lung cancer. Clin Cancer Res 13: 3229-3234, 2007

52. Bai Y, Xiong L, Zhu M, Yang Z, Zhao J and Tang $\mathrm{H}$ : Co-expression network analysis identified KIF2C in association with progression and prognosis in lung adenocarcinoma. Cancer Biomark 24: 371-382, 2019.

53. Song YJ, Tan J, Gao XH and Wang LX: Integrated analysis reveals key genes with prognostic value in lung adenocarcinoma. Cancer Manag Res 10: 6097-6108, 2018.

54. Daino K, Ugolin N, Altmeyer-Morel S, Guilly MN and Chevillard S: Gene expression profiling of alpha-radiation-induced rat osteosarcomas: Identification of dysregulated genes involved in radiation-induced tumorigenesis of bone. Int J Cancer 125: 612-620, 2009

55. Thutkawkorapin J, Picelli S, Kontham V, Liu T, Nilsson D and Lindblom A: Exome sequencing in one family with gastric- and rectal cancer. BMC Genet 17: 41, 2016.

56. Zhao G, Gong L, Su D, Jin Y, Guo C, Yue M, Yao S, Qin Z, Ye Y, Tang Y, et al: Cullin5 deficiency promotes small-cell lung cancer metastasis by stabilizing integrin $\beta 1$. J Clin Invest 129: 972-987, 2019.

57. Boudria A, Abou Faycal C, Jia T, Gout S, Keramidas M, Didier C, Lemaître N, Manet S, Coll JL, Toffart AC, et al: VEGF165b, a splice variant of VEGF-A, promotes lung tumor progression and escape from anti-angiogenic therapies through a $\beta 1$ integrin/VEGFR autocrine loop. Oncogene 38: 1050-1066, 2019.

58. Mitra SK, Hanson DA and Schlaepfer DD: Focal adhesion kinase: In command and control of cell motility. Nat Rev Mol Cell Biol 6: 56-68, 2005.

59. Hayashi I, Vuori K and Liddington RC: The focal adhesion targeting (FAT) region of focal adhesion kinase is a four-helix bundle that binds paxillin. Nat Struct Biol 9: 101-106, 2002.

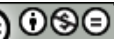

This work is licensed under a Creative Commons Attribution-NonCommercial-NoDerivatives 4.0 International (CC BY-NC-ND 4.0) License. 